\title{
Pet therapy and geriatrics: a social-sanitary connection
}

\author{
A Pugliese $^{1 *}$, L Famulari $^{1}, \mathrm{D}$ Britti $^{2}$ \\ From de Senectute: Age and Health Forum \\ Catanzaro, Italy. 5-7 December 2009
}

\section{Background}

The Pet therapy has effective intervention strategies to treat psycho-physics pathologies as well to improve life quality. Animals represent ethereal molecules capable of stimulating the release of neurotransmitters and various endogenous peptides with several mechanisms of action, mainly of emotional type, that promote an interconnection between affective and biological spheres, modifying the neuro-endocrine axis, and determining, through the biochemical-nervous pathways, the attainment of a state of well-being: eucenestesis. The aim of Pet Therapy is to ameliorate the state of well-being of some classes of patients and, among those, elderly people that, by means of contact with pets, experience a state of wellbeing connected to:

- biological mechanisms: activation of specific neurotransmitters produce a rise in the level of endorphins, a decrease in the levels of adrenalin and corticosteroids, and a decrease in the activity of cholinergic system;

- affective-emotional mechanisms (i.e. soul expressions): in men and superior animals neurons that fire both when the subject completes an action and when observes others that do the same action (mirror neurons) have been identified;

- physical mechanisms: responsible for the psychological boundary establishment of one's own identity, one's own self, and one's own existence;

- psychological mechanisms: by means of pets, man develops interpersonal relationships;

- associated mechanisms: single mechanisms interact with each other in a synergistic way and, thanks to factors that reduce the feelings of alienation and isolation such as the communication with other people, the recall of memories, the entertainment, and the play, determine a cerebral stimulation.

The contact with pets is also effectual on behavioral parameters reducing excitement, stimulating creativity, curiosity, and observational ability; and on affectivity ameliorating depression and anxiety. Besides age-associated pathologies (i.e. hypertension, diabetes, cardio- and broncho-pathies), elderly people show discomforts (i.e. retirement, and consequent loss of the social position, mourning and/or stressful events, home change, hospitalization in old's people home, loss of social and emotional entourage) that cause an increase of anxiety, depression, and physiologic cognitive impairment.

\section{Conclusions}

The use of pets in geriatrics represents a proper true drug both in the prevention and in the therapy of pathological conditions that require long hospitalization periods such as mental impairment due to old age and Alzheimer's.

\section{Author details}

${ }^{1}$ Pet Therapy Center, University of Messina, 98100, Italy. ${ }^{2}$ Department of Clinical and Experimental Medicine, University of Catanzaro "Magna Graecia", 88100 , Italy.

Published: 19 May 2010

\section{References}

1. Pugliese A: Pet Therapy Strategie d'intervento e linee guida. Armando Editore 2005,

2. Kongable LG, Buckwalter KC, Stolley JM: The effects of pet therapy on the social behavior of institutionalized Alzheimer's clients. Arch Psychiatr Nurs 1989, 3:191-198.

doi:10.1186/1471-2318-10-S1-L25

Cite this article as: Pugliese et al:: Pet therapy and geriatrics: a socialsanitary connection. BMC Geriatrics 2010 10(Suppl 1):L25.

'Pet Therapy Center, University of Messina, 98100, Italy 